\title{
Interlocução na Produção de Cartas Pessoais na Sala de Mula
}

\author{
The Interlocutor in the Production of Personal Letters \\ in Classroom
}

Ednéia Aparecida Bernardineli BERNINI *
Renilson José MENEGASSI **

Resumo: Ao considerar uma concepção de ensino-aprendizagem embasada no discurso como prática social, experiências em leitura e escrita em sala de aula tornam-se mais significativas, pois recursos que possibilitem ao aluno assumir uma atitude dialógica são valorizados. Nesta perspectiva, este artigo tem como objetivo analisar a presença do Interlocutor/Outro em cartas pessoais de alunos de $8^{a}$ série do ensino fundamental de uma escola privada do município de Marialva-Paraná. Analisar-se-á, principalmente, a presença de marcas de interlocutor real e interlocutor real externo, já que a proposta delimitava um destinatário. Mesmo assim, são observadas marcas direcionadas a um interlocutor virtual e ao interlocutor interno. Para subsidiar esta análise, recorrem-se a leituras e a conceitos desenvolvidos pelo Círculo de Bakhtin e por pesquisadores brasileiros que abordam essa teoria. O que ficou evidenciado foi uma constante nas marcas da presença de interlocutor real externo, mas também, algumas evidências de escrita para um interlocutor real além de marcas insignificantes de interlocutor virtual e nenhuma marca

\footnotetext{
* Doutoranda em Estudos da Linguagem pela Universidade Estadual de Londrina. Mestre em Linguística Aplicada pela Universidade Estadual de Maringá (2003). Atualmente é professora da Associação Cultural e Social Anjos Custódios e professora da Rede Pública Estadual de Educação Básica - QPM no Colégio Estadual Dr. Felipe Silveira Bittencourt. Contato: edneiaabbernini@hotmail.com.

** Possui Pós-Doutorado em Linguística Aplicada pela Universidade Estadual de Campinas. Doutor em Letras pela Universidade Estadual Júlio de Mesquita FilhoAssis. Mestre em Linguística na Universidade Federal de Santa Catarina. Atua como docente e pesquisador na Universidade Estadual de Maringá. Contato: renilson@wnet.com.br.
} 
de interlocutor interno. Os resultados da análise comprovam que ainda falta uma maturidade do emprego dos elementos constitutivos de um texto, inclusive, do interlocutor.

Palavras-chave: Escrita. Interlocutor. Carta pessoal.

Abstract: Considering a teaching-learning conception based on the discourse as a social practice, experiences in reading and writing in classroom become more meaningful, because resources that allow the student to assume a dialogic attitude are valued. In this perspective, this paper aims to analyze the presence of the interlocutor/other in personal letters of students from the eighth grade / elementary school of a private school of the municipality of Marialva - Paraná. The presence of traces of a real interlocutor and an external real interlocutor will be analyzed, since the proposal requested a receiver. Even so, a virtual and an internal interlocutor are observed. To support this analysis, readings and concepts developed by the Circle of Bakhtin and by Brazilian researches that approach this theory were used. What is evident was the constant traces of a real external interlocutor, but, also, some writing evidences for a real interlocutor, in addition to the insignificant traces of a virtual interlocutor and no trace of an internal interlocutor. The results of the analysis show that the students do not show maturity in the use of the elements of a text, including, the interlocutor.

Key words: Writing. Interlocutor. Personal letter.

\section{Considerações Iniciais}

Ao assumir a concepção de que a enunciação é de natureza social, considera-se também a linguagem como uma atividade de interlocução que se realiza em diferentes instâncias sociais e se desenvolve em um processo real de trabalho linguístico-discursivo, inserido num contexto social com interlocutores certos. Assim, prima-se por um discurso dirigido a alguém, numa situação real de comunicação, que expresse uma intenção ou uma vontade discursiva (BAKHTIN, 2003), distanciando-se da artificialidade, muitas vezes observada em situações de ensino e aprendizagem.

Dentro dessa abordagem, foi proposta a alunos de uma sala de $8^{\mathrm{a}}$ série do ensino fundamental, de uma escola privada do município de Marialva, Paraná, a produção de uma carta pessoal para um interlocutor real - 
professora de Geografia. Cabe destacar que este estudo tem por objetivo analisar a presença do interlocutor/outro na escrita desses alunos, considerando-o como: interlocutor real e interlocutor real externo, já que a proposta para a escrita da carta delimitava um destinatário definido. De acordo com Franzoi (2009, p. 79), a partir dos estudos do Círculo da Bakhtin, "O interlocutor é real quando pertence ao mesmo contexto social do locutor, que se encontra presente no momento da constituição do enunciado e influencia diretamente na elaboração do discurso tanto oral quanto escrito, devido a sua presença face a face.". Já o interlocutor real externo não participa do momento de elaboração do texto, mas é para ele direcionado efetivamente. Além disso, buscaram-se, nas cartas produzidas, marcas discursivas de interlocutor virtual, aquele que sabemos de sua existência, porém não há como prová-la no momento da produção do discurso, que não participa do processo dialógico, ou ainda um interlocutor interno, o próprio aluno. É preciso ressaltar que, para este trabalho, considerou-se o interlocutor/outro como uma das principais características para a construção da escrita. Entretanto, a enunciação depende, primeiramente, da finalidade, ou seja, uma razão para escrever, que resulta na seleção do gênero textual (BAKHTIN, 2003).

Para a escrita da carta, os alunos selecionam palavras (que podem ser ditas) do contexto da vida ou do contexto escolar em que estão inseridos, impregnados de julgamentos de valor (VOLOSHINOV/BAKHTIN, 1976). Além disso, cabem aqui as adequações de conteúdo temático, o estilo e a construção composicional que atendam a proposta: escrever uma carta pessoal para despedir-se da professora de Geografia, que não daria mais aulas para os alunos da $8^{a}$ série. A carta pessoal, ao estar presente em situação escolar, ao ser solicitada pela professora de Língua Portuguesa, passa a perder a sua significação real, mesmo com a finalidade de ser entregue a um interlocutor real externo, passa a fazer parte de uma situação escolar, pois os alunos só escreveram porque foi solicitado, não foi algo espontâneo. $\mathrm{O}$ enunciado concreto, no caso a carta, nasce, vive e morre no processo da interação social entre os participantes da enunciação - alunos e professora de Geografia - (VOLOSHINOV/BAKHTIN, 1976, p. 9), via professor de Língua Portuguesa, mesmo sabendo-se da artificialidade ali presente.

O referencial teórico deste trabalho está embasado na perspectiva da Linguística da Enunciação, apoiando-se na concepção dialógica de linguagem, com ênfase na abordagem sócio-histórica, dentro da perspectiva da 
Linguística Aplicada, com pressupostos teóricos de Bakhtin e pesquisas desenvolvidas no Brasil sob esta base teórica. Logo, buscou-se assumir a concepção de linguagem como prática que se efetiva nas diferentes instâncias sociais, como preconizam as Diretrizes Curriculares da Educação Básica Língua Portuguesa, DCE/LP (PARANÁ, 2008).

\section{A Interação e o Outro}

Os estudos do Círculo de Bakhtin auxiliam na compreensão da noção de gênero discursivo. Nas obras Marxismo e Filosofia da Linguagem (1992) e Estética da Criação Verbal (2003), apresenta-se teoria acerca dos gêneros do discurso, inicialmente discutindo-se sobre uma vertente literária, mas não somente por este viés. Para ele, toda atividade humana se estabelece na relação com a língua e a utilização desta se dá por meio de enunciados, os quais refletem as condições específicas e as finalidades de cada esfera de atividade humana.

Segundo Bakhtin (2003), o enunciado particular é individual, mas os campos de utilização da língua elaboram 'tipos relativamente estáveis' de enunciados e são esses enunciados que o autor denomina de gêneros do discurso. Para ele, o reconhecimento de um gênero se dá pela identificação de três elementos: conteúdo temático; construção composicional e estilo. A riqueza e a diversidade dos gêneros do discurso são infinitas, pois são inesgotáveis as possibilidades de atividade humana, por ser de natureza dialógica, realiza-se por meio de palavras que são direcionadas ao outro em busca de sua contrapalavra. Essa interação constitui a verdadeira essência da língua.

A verdadeira substância da língua não é constituída por um sistema abstrato de formas lingüísticas nem pela enunciação monológica isolada, nem pelo ato psicofisiológico de sua produção, mas pelo fenômeno social da interação verbal, realizada através da enunciação ou das enunciações. A interação verbal constitui assim a realidade fundamental da língua. (BAKHTIN/VOLOCHINOV, 1992, p. 123, grifos do autor).

Além disso, "[...] toda palavra comporta duas faces. Ela é determinada tanto pelo fato de que procede de alguém, como pelo fato de que se dirige 
para alguém. Ela constitui justamente o produto da interação do locutor e do ouvinte." E mais "Toda palavra serve de expressão a um em relação ao outro." (BAKHTIN/VOLOCHINOV, 1992, p. 113, grifos do autor).

Assim, tudo o que é dito ou escrito acontece em função desse outro que se quer atingir - ouvinte, leitor, em uma determinada situação social.

Um dos princípios da teoria do Círculo de Bakhtin é o interlocutor (BAKHTIN/VOLOCHINOV, 1992) ou o outro (BAKHTIN, 2003) sobre os quais Franzoi (2009, p. 16) atentou:

[...] termo 'interlocutor' é utilizado, com maior frequência, na obra de Bakhtin/Volochinov (1995), ao contrário do que se observa em Bakhtin (2003), que apresenta o termo 'outro', ao referir-se àquele que estabelece a compreensão responsiva ativa no processo de interação verbal.

Já na obra Discurso na vida e discurso na arte, Voloshinov/Bakhtin (1976, p. 14), tratam-no, além de interlocutor, especialmente como "ouvinte": "A interrelação de autor e herói, afinal, nunca é realmente uma relação íntima de dois; todo o tempo a forma leva em conta o terceiro participante - o ouvinte - que exerce influência crucial em todos os outros fatores da obra". Assim, três denominações são observadas cronologicamente: ouvinte interlocutor - outro.

Para esses autores russos, mais uma vez, interlocutor e/ou outro podem ser definidos como ouvintes não passivos, mas participantes ativos da comunicação discursiva; dele espera-se uma ativa compreensão responsiva, pois o enunciado é construído para que se obtenha essa resposta; o discurso sempre se dirige ao outro que pode ser um interlocutor direto, uma coletividade e, ainda, pode ser um outro não concretizado (virtual), porém passível de existência. Não pode haver interlocutor abstrato, pois não se teria linguagem comum com tal interlocutor e mesmo que não haja um interlocutor real, este pode ser substituído pelo representante médio do grupo social ao qual pertence o locutor (BAKHTIN/VOLOCHINOV, 1992). Sem o direcionamento, o endereçamento, o enunciado não pode existir, pois o processo de enunciação se dá, primeiramente, com a definição de um objetivo para, depois, determinar o interlocutor que influenciará e determinará o gênero discursivo a ser utilizado e o seu estilo. Esse objetivo é, na verdade, a finalidade para a produção. Neste trabalho, o gênero 
discursivo, bem como a finalidade e o interlocutor, foram determinados pela professora de Língua Portuguesa: despedir-se da professora de Geografia por meio de uma carta pessoal endereçada diretamente a ela.

De acordo com Bakhtin/Volochinov (1992, p. 112), "a enunciação é o produto da interação de dois indivíduos socialmente organizados [...] a palavra dirige-se a um interlocutor", isto significa que a interlocução é o princípio da interação. Além disso, "variará se se tratar de uma pessoa do mesmo grupo social ou não, se esta for inferior ou superior na hierarquia social, se estiver ligada ao locutor por laços sociais mais ou menos estreitos (pai, mãe, marido, etc.)" (BAKHTIN/VOLOCHINOV, 1992, p. 112). Mais uma vez, neste trabalho, pode-se considerar o interlocutor, a quem foi escrita a carta - a professora de Geografia, com quem os alunos conviveram por mais de três anos, como um interlocutor real externo, pois está próximo do horizonte social dos alunos e por meio da enunciação ocorrerá a comunicação verbal, o fenômeno social da interação verbal, considerando-se a existência da professora, a interlocutora real, na sala de aula. Dessa forma, estabelece-se aqui a perspectiva de realização da interlocução em sala de aula a partir da existência de dois interlocutores reais: a) a professora de Língua Portuguesa, interlocutora real; b) a professora de Geografia, interlocutora real externa, expandindo-se as categorias de interlocução propostas pelo Círculo de Bakhtin.

Cronologicamente, houve aprofundamento na caracterização do interlocutor/outro pelo Círculo de Bakhtin, o que pode ser visualizado pelo Quadro 1, que delineia os aspectos que cada obra deu a esse elemento.

Enquanto na primeira obra, o interlocutor é um dos participantes do jogo da entoação, ou seja, do jogo enunciativo, mas ainda como "convidado", como "testemunha e aliado" (VOLOSHINOV/BAKHTIN, 1976 , p. 8, grifos do autor), na segunda, ele aparece como "indivíduos socialmente organizados" (BAKHTIN/VOLOCHINOV, 1992, p. 112) e, na sequência, como participante "real", "imediato", "ativo" da comunicação discursiva (BAKHTIN, 2003). Tudo isso, permite-nos inferir que o interlocutor/outro foi ganhando destaque na teoria da enunciação, ocupando, realmente, "uma ativa posição responsiva" (BAKHTIN, 2003, p. 271), como um dos principais elementos do dialogismo.

Nas três obras fica clara a influência direta que o interlocutor/outro exerce na produção. Para o interlocutor, obra é orientada e, por isso, determinará sua estrutura, o estilo e as escolhas dos recursos linguísticos. 
Quadro I - Caracterização cronológica do interlocutor/outro nas obras do Círculo de Bakhtin

\section{- Discurso na vida e discurso na arte (VOLOSHINOV/BAKHTIN,} 1976):

- O interlocutor é um dos participantes do jogo da entoação, é um convidado, é como uma testemunha e aliado. (p. 8);

- aquele a quem a obra é orientada e que, por consequência, intrinsecamente determina a estrutura da obra. (p. 13);

- tem seu lugar próprio, independente no evento, deve ocupar uma posição bilateral em relação ao autor e ao herói (p. 14);

- é um fator intrínseco essencial, de modo algum coincide com o público leitor (p. 15);

- participante constante na fala interior e exterior de uma pessoa (p. 16).

- Marxismo e filosofia da linguagem (BAKHTIN, M./VOLOCHINOV, V. N., 1992):

- Pode pertencer a mesma comunidade linguística do locutor (p.93); do mesmo horizonte social (p.112);

- um dos indivíduos socialmente organizados que faz parte da interação verbal (p. 112);

- determinará, orientará a forma e o estilo da enunciação (p.112);

- é concreto (p.112).

- Estética da criação verbal (BAKHTIN, M., 2003):

- Ocupa uma ativa posição responsiva (p. 271);

- participante real da comunicação discursiva (p. 272);

- um dos sujeitos do discurso, parceiros do diálogo (p. 275);

- um dos participantes imediatos da comunicação, que se orienta na situação e nos enunciados antecedentes, abrange fácil e rapidamente a intenção discursiva, a vontade discursiva do falante, e desde o início do discurso percebe o todo do enunciado em desdobramento. (p. 282);

- para quem se constrói e se direciona o enunciado (p. 301);

- não são ouvintes passivos, mas participantes ativos da comunicação discursiva (p.301);

- pode ser um participante-interlocutor direto do diálogo cotidiano, pode ser uma coletividade diferenciada, pode ser um público mais ou menos diferenciado, pode ser totalmente indefinido, não concretizado (p. 301); - influencia as escolhas dos recursos linguísticos feitas pelo falante (p. 306). 
Adotando a mesma perspectiva enunciativa de Bakhtin, pesquisadores brasileiros discutem e aplicam essa teoria em novas pesquisas, e algumas delas são aqui expostas. Ademais, o documento oficial sobre educação do Paraná, as Diretrizes Curriculares da Educação Básica - DCE (PARANÁ, 2008), também se apresenta com esta perspectiva.

Ao expor e discutir o conteúdo estruturante da disciplina de Língua Portuguesa, tendo o discurso como prática social, as DCE retomam a teoria de Bakhtin:

O discurso é efeito de sentidos entre interlocutores, não é individual, ou seja, não é um fim em si mesmo, mas tem sua gênese sempre numa atitude responsiva a outros textos (BAKHTIN, 1999). Discurso, aqui, é entendido como resultado da interação - oral ou escrita entre sujeitos, é 'a língua em sua integridade concreta e viva' (BAKHTIN, 1997, p. 181). (PARANÁ, 2008, p. 63).

No processo dialógico da linguagem, viva e em evolução, os sujeitos se constituem, o que foi destacado por Souza (2010, p. 64): “A isso corresponde compreender que o homem é um ser de relações e se liga uns aos outros no espaço da linguagem". A autora, ao analisar e comparar os conceitos bakhtinianos tratados em cada versão das DCE, detecta que este documento, ao referir-se ao conceito de texto, "se posiciona com uma visão desse elemento para além da sua condição de materialização do discurso, aproximando-se da ideia de enunciação porque envolve diálogo entre interlocutores e o contexto sócio-histórico em que está imerso" (SOUZA, 2010 , p. 83). Logo, a carta produzida na situação de ensino aqui proposta é um diálogo entre alunos e professora de Geografia, imersos em um contexto sócio-histórico real.

Nas análises e comparações feitas por Souza (2010), o conceito de interlocutor é utilizado ao referir-se ao conceito mais amplo que é o discurso: "Efeito de sentidos entre interlocutores, não é individual, não é um fim em si mesmo" (SOUZA, 2010, p. 94). Mesmo assim, de acordo com a autora, alguns conceitos referentes à teoria enunciativa de linguagem não foram aprofundados nas DCE, o que, se não compreendidos, poderia comprometer a efetivação de práticas pedagógicas embasadas nesta teoria, inclusive o conceito de discurso, visto pela autora como preocupante, por ser este o conteúdo estruturante da disciplina de Língua Portuguesa no documento oficial do Paraná. 
Menegassi e Fuza (2006), ao analisar, em livros didáticos de Língua Portuguesa de $5^{\mathrm{a}}$ a $8^{\mathrm{a}}$ séries os comandos de escrita que possuem a finalidade de escrita marcada no interlocutor, observam de que forma a imagem do interlocutor pode influenciar na produção textual do aluno. Os autores verificaram que a maioria das propostas promove uma finalidade artificial de escrita, levando o aluno a escrever para demonstrar sua competência de escrita, tendo uma minoria de comandos que possibilita uma finalidade real de escrita por meio de interlocutores que não se constituem apenas como avaliadores de seu texto, normalmente o professor e o colega de sala. $\mathrm{Na}$ proposta de escrita da carta pessoal, evitou-se essa artificialidade, visto que os alunos escreveram para um destinatário real externo à sala de aula de Língua Portuguesa, contudo, real, existente - professora de Geografia.

Para Garcez (1998), a figura do destinatário tem tanto a função de quem recebe, como também a de quem permite ao locutor perceber seu próprio enunciado, já que a palavra se orienta em função do interlocutor e da cadeia dialógica sócio-histórica, este é parceiro no diálogo e assim determina sua configuração, ou seja, o sujeito que enuncia constitui para si um possível destinatário e, de certa forma, se constitui também, transitoriamente, como esse possível destinatário, num processo dinâmico e complexo de inserção na rede comunicativa que se estabelece no sistema social. Dessa forma, não há apenas um destinatário real, concreto, identificável; nem apenas mais um destinatário virtual, secundário, possível, ideal; há também um destinatário terceiro que sobrepaira o próprio diálogo e é formado por um conjunto ideológico ao qual o autor pertence e ao qual quer satisfazer, responder, refutar, contradizer (BAKHTIN/ VOLOCHINOV, 1992). Na pesquisa de Garcez (1998), uma das perguntas feita aos alunos era: 'Que representação você possui do interlocutor virtual?'. E dos setenta e dois questionários analisados pela pesquisadora, apenas em dois houve uma preocupação explícita com o destinatário, nenhum dos alunos apresentou uma definição do seu interlocutor enquanto ser socialmente marcado. Fato este que embasa a importância dada, neste trabalho, com os alunos da $8^{a}$ série, a presença do interlocutor real externo.

Rojo (2005), ao diferenciar gêneros do discurso e gêneros textuais, e ao apresentar os elementos essenciais da situação social, destaca que são as relações sociais, institucionais e interpessoais entre locutor/interlocutor, vistas a partir do foco da apreciação valorativa do locutor, que determinam muitos aspectos temáticos, composicionais e estilísticos do texto ou discurso. Zanini 
(2009) ratifica que o público-alvo é quem determina o nível de profundidade com que são tratados o assunto e o tema, para a escolha lexical e organização linear do texto, portanto, o estilo. Freitas (2006) reafirma a ideia de que o enunciado se produz num contexto que é sempre social, não sendo necessária a presença atual do interlocutor, mas pressupondo-se a sua existência. "O ouvinte ou leitor é assim um outro - presença individual ou imagem ideal de uma audiência imaginária” (FREITAS, 2006, p. 135).

Marchezan e Motta Roth (2011) reiteram que a relação de identificação com o destinatário é muito importante para efetivar a comunicação. Por meio de entrevista com duas editoras e questionários aplicados a professores universitários, elas comprovam isso, analisando o gênero contracapa, o seu processo de constituição, suas características, a finalidade desse gênero e relevância para o meio acadêmico, enfim "o surgimento da contracapa é motivado pelos interesses da comunidade acadêmica, o qual se constitui em enunciados pertencentes à esfera social da comunidade acadêmica, que darão suporte para a construção do discurso do gênero" (MARCHEZAN; MOTTA-ROTH, 2011, p. 8). Na composição da contracapa do livro, o interlocutor é considerado como um dos elementos importantes desse processo.

Para Menegassi (1997), a presença do interlocutor no discurso do aluno interfere na produção, pois este modifica e adapta o discurso em relação ao seu interlocutor; fato comprovado em pesquisa realizada com produções textuais de professores, em que a maioria dos textos apresentou marcas explícitas de interlocução. Em outro trabalho desenvolvido por esse pesquisador (MENEGASSI, 2003), por meio de construção de comandos de produção de textos por professores de uma instituição privada de Maringá-PR, em que foram abordados os elementos que devem ser considerados na construção do texto, entre eles, o interlocutor, e, mesmo recebendo teorias acerca da importância desses elementos, antes da produção dos comandos, um grande número deles apresentou problemas com determinação do interlocutor, o que geraria problemas na construção textual por parte dos alunos. $\mathrm{O}$ aluno precisa receber um comando que contemple todos os elementos para a construção textual, ou seja, em uma interação comunicativa, tendo o que dizer, uma razão para dizer o que se tem a dizer, para quem dizer o que se tem a dizer (GERALDI, 1997).

Franzoi (2009), em pesquisa com alunos de $7^{\mathrm{a}}$ série, em produções de crônica, diagnosticou que, ao não se delimitar o interlocutor nos comandos 
de produção textual, os educandos demarcam vários outros participantes num mesmo enunciado. Além disso, a omissão da imagem do outro propiciou que os alunos definissem a professora da sala de aula como interlocutor/real com função de avaliadora, comprometendo a continuidade de um processo dialógico e a compreensão responsiva ativa. Ao ser exposta a finalidade e o interlocutor, detectou-se uma preocupação em como produzir a crônica, os educandos se atentaram à delimitação do seu interlocutor para qual era encaminhada a sua palavra escrita, adequando-a segundo a imagem desse outro. Portanto, nos comandos de escrita, deve haver um interlocutor definido, que propicie a exauribilidade do objeto e do sentido; a delimitação discursiva, das formas composicionais e do gênero do acabamento, favorecendo a compreensão responsiva ativa.

\section{O Interlocutor na Carta Pessoal}

Antes da proposta da Carta Pessoal, foi desenvolvida uma primeira atividade de revisão das características discursivas desse gênero e feitos breves comentários sobre a saída da professora Cleide (nome fictício), visto que ela já havia informado os alunos. Buscou-se, por meio desta proposta, romper a barreira da artificialidade das situações de escrita, mediante a proposta de escrita em que os alunos se sintam sujeitos de seus textos, pois lhes possibilitou a produção de um texto autêntico, com finalidade específica por meio de uma situação de comunicação o mais próxima do real possível. Por isso, decidiu-se pela proposta, conforme comando: "A fim de se despedir da Prof. a de Geografia, Cleide, que não dará mais aula para vocês, produza uma carta pessoal em folha de caderno para ser entregue a ela.".

Alguns alunos questionaram se a carta seria realmente entregue e, após ouvirem a resposta afirmativa, outros perguntaram se valeria nota, o que foi confirmado pela professora de Língua Portuguesa, aproveitando o momento e a situação, como estímulo.

Reafirma-se que este estudo tem por objetivo analisar a manifestação do interlocutor na escrita dos alunos, considerando os seguintes interlocutores e suas características:

a) o interlocutor real: professora de Língua Portuguesa, presente no processo dialógico, pois foi quem aplicou a atividade e a avaliou, logo podem aparecer marcas dirigidas a ela ou de suas falas, recortadas das aulas, no texto escrito; 
b) o interlocutor real externo: professora Cleide para quem os alunos escreveram, não estando presente no momento de elaboração da carta;

c) o interlocutor interno, ou seja, o próprio aluno;

d) interlocutor virtual também era uma possibilidade, mesmo com um comando que determinava o interlocutor real externo.

Ao analisarmos as cartas, a sua compreensão e ou a sua avaliação são possíveis se for considerada a situação pragmática extraverbal juntamente com o discurso verbal. Bakhtin (2003) e Bakhtin/Volochinov (1992) destacam que o locutor, ao constituir um enunciado, necessita da interação com o interlocutor, que deve estar organizado social e historicamente, para criar limites precisos aos discursos; representados pelo espaço comum que os sujeitos constroem na própria interação, portanto, somente inserido em um contexto social e histórico é que as cartas dos alunos de $8^{a}$ série possuem significação - despedir-se da professora de Geografia, que não dará mais aula, com quem conviveram desde o segundo semestre de 2008 até 2011. Ressalta-se que, ao citar trechos das cartas dos alunos, estes são identificados pelas iniciais de seus nomes e são transcritos exatamente como foram produzidos, pois não houve correção e reescrita, em função da proximidade do recesso escolar à época e por não ser o objetivo da experiência.

A atividade foi aplicada no dia 27 de junho de 2011; por ser um dia bastante frio, sete alunos faltaram e, ao fazer a leitura dos 33 textos produzidos, percebemos que vinte mantiveram a enunciação apenas em primeira pessoa do singular, os demais, treze, misturavam primeira pessoa do singular e primeira do plural:

Você foi uma ótima professora, e sei que, quando voltar a dar aulas, seus futuros alunos vão gostar muito de você, assim como eu e o restante dos alunos gostamos de você. (C.Y.I.).

Observe que a aluna se dirige à professora através dos pronomes "você", por três vezes, e "seus", enquanto a si própria se refere em pessoas discursivas diferentes: "sel" e "eu" (primeira pessoa do singular) e "gostamos" (primeira pessoa do plural). Essa mistura discursiva não alterou o diálogo com a professora de Geografia, ao contrário, deixou a carta até mais pessoal.

Quase todos os alunos dirigem-se à professora por meio do pronome de tratamento "Você" e apenas uma aluna (I.B.C.) refere-se à professora com pronomes "você e senhora", mesmo ela sendo bem jovem, marcando 
esse interlocutor com um discurso respeitoso, por ser uma autoridade em sala, provavelmente, também, pela educação recebida pela família:

desejo toda a felicidade do mundo pra senhora nessa caminhada, que você tenha muito sucesso na sua vida pessoal e profissional.

Todos apresentam marcas do interlocutor real externo, pois todos fizeram elogios à professora de Geografia, a quem a carta foi direcionada; apenas dois alunos apresentaram alguma crítica:

Queria agradecer tudo o que vocêfezpor mim ao longo desses quase três anos e meio, todas as broncas, todas as perguntas e respostas que apesar de serem meio chatinhas me ajudaram MUITO na hora de estudar. (V.V.A.)

Gostaria que você soubesse que você foi uma das melhores, e mais gente boa professora que já tive, que eu adorava suas aulas, mas também tinha algumas que eu odiava.. (G.A.R.B.).

Apareceram várias referências às broncas dadas em sala, aproveitando a oportunidade da escrita para pedir desculpas. Isso pode ser considerado também uma marca do interlocutor real - professora de Língua Portuguesa, pois sabiam que esses elogios também a agradariam, pois ela iria ler antes de encaminhar à professora Cleide e que cartas de despedida com elogios seriam mais polidas, além de ser também uma das características desse gênero, a exposição pessoal. Isso não foi explicado no momento de aplicação, mas ficou bem marcado, ratificando a teoria de que "A palavra está sempre carregada de um conteúdo ou de um sentido ideológico ou vivencial" (BAKHTIN/VOLOCHINOV, 1992, p. 95).

Os alunos sabiam o motivo da saída da professora no final do semestre, fazer o doutorado, mas apenas dez retomam-no em seu discurso:

eu desejo a você, muitas felicidades, espero que tenha sucesso no seu doutorado e principalmente não esqueça de nós, (I.P).

Isso confirma a participação real, imediata do outro como um dos sujeitos do discurso.

Alguns apresentaram características bem pessoais da professora, escrevendo, portanto, para um interlocutor real externo ao processo dialógico: 
Eu nunca vou esquecer do seu jeito de falar meio 'rapidinho'. (B.R.P. G.)

Gostava desse seu jeito meigo e delicada de ser (L.S.Y.);

vou sentir falta de suas broncas e de seus looks maravilhosos (C.S.S.).

Mais uma vez, há marcas claras para quem se construiu e se direcionou o enunciado.

Algumas marcas de pessoalidade também comprovam esse direcionamento do discurso para um interlocutor real externo-professora Cleide:

Não foi uma despedida pra sempre, porque podemos conversar pelo MSN (A.F.);

Agora que você não da mais aula para nós, eu posso confessar que todas as suas aulas en estava com chiclete, tomara que não fique brava hahaha. [...] usava aquela 'bendita' planilha quando precisava e também aquela sua agenda (V.S.);

Quero te desejar um ótimo futuro, que você, com esse jeitinho meio doidinha, brincadeira, realize todos os seus sonhos (M.S.);

Também gostaria de te dizer que nunca abri os e-mails que voce mandou (G.A.R.B.).

Essas marcas confirmam o que Souza (2010, p. 74) afirma: “desde o princípio, evidencia-se o papel do outro, isto é, aquele a quem o dizer é endereçado e em função de quem o discurso é estruturado".

Durante o processo de construção da carta, vários alunos perguntaram quem iria substituir a professora de Geografia e, como essa informação ainda não era conhecida pela professora de Língua Portuguesa, ela não pode informá-los, e isso também acaba aparecendo em algumas cartas, reforçando a presença do interlocutor real - professora de Língua Portuguesa, pois fora uma informação transmitida a eles:

você foi muito importante e ninguém que vier te substituir vai ser igual (E.F.B.)

Espero que o professor (a) que ira te 'substituir' seja bom, pois voce é insubstituivel. (C.I.S.) 
nunca ninguém vai substituir o seu trabalho nem sua simpatia. (M.P. N.)

quando outro professor ou professora entrar na nossa sala, sempre lembrarei de você. (L.S.Y.).

Em "Tenho certeza de que nenhum professor de Geografia será melhor que a professora” (A.F.), mesmo se dirigindo à professora de Geografia, utilizando o pronome "você" e escrevendo em $1^{\mathrm{a}}$ pessoa, ocorre esse distanciamento, como se estivesse escrevendo para outra pessoa, para um interlocutor virtual, ao empregar ao final o substantivo "professora" para se referir à interlocutora eleita. Além disso, apenas cinco alunos retomam o nome da professora de Geografia no corpo do texto, os demais apenas o apresentam no vocativo, mantendo o distanciamento e tratando-a por 'professora', outra característica do gênero solicitado. Este fato confirma que os papéis sociais determinam a conduta e regulam os modos de dizer, pois o enunciado é sustentado pela situação comunicativa imediata, influenciando as escolhas dos recursos linguísticos, consequentemente determinando o estilo de linguagem empregado.

Para melhor exemplificar essa proposta, selecionaram-se dois textos, os quais são transcritos na íntegra, tal como o aluno produziu, com marcas bem distintas, como mostras representativas das produções.

\section{Texto 1}

Marialva, 27 de junho de 2011

Oi, coisa fofa!

Tudo bem? Eu queria dizer que você é uma ótima professora, e uma perfeita amiga, e queria dizer que eu irei sentir muito sua falta, das brincadeiras, e até das broncas que você me dava, vou sentir falta das suas aulas, das vezes que você chamava agente de 'pessoas', quero que você saiba eu gosto muito de você, sei que eu não demonstrava muito bem isso, porque eu me sentia meio acanhada, mas agora não tenho o porque de não falar, as suas aulas sempre foram muito legais, para falar a verdade a sua matéria é uma das muitas poucas que eu tiro nota, fazer o que né, preciso disso pra ser uma 
astronoma, em fim queria agradecer por tudo porque além de ser uma professora e uma amiga você é um exemplo com a sua sinceridade, seu jeito e suas roupas lindas, não sei se você se lembra mas eu vivia falando dos seus maravilhosos sapatos, mas acho que você não gostava muito. Espero que continuemos nos falando atravez do orkut, MSN dentre outros meios de comunicação que encurtam as distancias. Obrigado por tudo, coisa linda, beijos G.R.R.

Esse texto comprova que a aluna escreveu considerando os dois interlocutores reais já descritos: o real e o real externo. O interlocutor real externo pertence ao mesmo contexto social do locutor, a quem ela se dirige como "Coisa fofa!" e "coisa linda", tratamento que já era dado à professora em momentos reais de sala, conforme informado pela aluna, ao ser questionada do porquê do emprego desse tratamento. Logo, esse interlocutor influenciou na constituição do enunciado, mesmo não se encontrando no momento do processo dialógico, assim como em: "Vou sentir falta das suas aulas, das vezes que você chamava agente de "pessoas" ", isso demonstra a capacidade do produtor de buscar em sua memória de vida não só a pessoa, como também suas próprias características. Em “Tudo bem?” observa-se uma marca de diálogo entre o locutor e o interlocutor, resgatando os conceitos arrolados por Bakhtin/Volochinov (1992), ao afirmar que o enunciado se constitui de acordo com a delimitação do interlocutor.

Há também direcionamentos específicos ao interlocutor real externo: "você é um exemplo com a sua sinceridade, seu jeito e suas roupas lindas, não sei se você se lembra mas eu vivia falando dos seus maravilhosos sapatos, mas acho que você não gostava muito." E na sequência "Espero que continuemos nos falando atravez do orkut, MSN dentre outros meios de comunicação que encurtam as distancias." A aluna informa e faz uma pergunta indireta: "não sei se você se lembra mas eu vivia falando dos seus maravilhosos sapatos" e, logo em seguida, completa com uma adversativa, que lhe serve como resposta: "mas acho que você não gostava muito" em função, provavelmente, de alguma manifestação da professora. Outro direcionamento específico para a professora de Geografia está em: "para falar a verdade a sua matéria é uma das muitas poucas que eu tiro nota, fazer o que né, preciso disso pra ser uma astronoma". Ainda neste excerto, encontramos marcas 
da linguagem oral, “fazer o que né,", considerados por Garcez (1998, p. 134) como "elos que exercem sobre o outro um poder de mobilização da atividade dialógica".

Pode-se encontrar no excerto "Espero que continuemos nos falando atravez. do orkut, MSN dentre outros meios de comunicação que encurtam as distancias" um direcionamento a um interlocutor virtual, pois se trata de uma enunciação consagrada pelo senso comum.

As marcas discursivas da carta analisada demonstram as relações pessoais da aluna com a professora. Então, observa-se que não são apenas os elementos linguísticos que manifestam essa interlocução, mas também, o compartilhamento de informações comuns à produtora e à interlocutora. Dessa forma, evidenciam-se como marcas discursivas enunciativas próprias da interlocução algumas aspectos:

- a professora dava broncas nos alunos;

- a professora denominava os alunos de "pessoas";

- a aluna sentia-se acanhada nas aulas da professora;

- a aluna conseguia boas notas na disciplina de Geografia;

- a aluna quer ser astrônoma;

- a professora usava "roupas lindas" e "sapatos maravilhosos" em sala de aula;

- a aluna admirava as roupas e os sapatos da professora.

Essas informações também constituem a imagem do outro no processo discursivo da carta produzida.

O Texto 2, por sua vez, se diferencia do anterior e mantém certo distanciamento do interlocutor, por característica própria de seu autor:

Texto 2

Marialva, 27 de Junho de 2011

Querida professora Cleide, Me despeço nesta carta de uma professora que me ensinou a gostar de geografia, que estudar também pode ser legal, eu te acho uma otima profissional, as vezes brava, mas eu gosto muito de você, não sei se irei gostar de geografia sem você estar ensinando, mas fico feliz e espero que 
consiga terminar o seu doutorado com sucesso e volte a dar aula para a gente.

Boa sorte, saudades

D.H.G.

Mesmo sendo uma proposta com finalidade, interlocutor e gênero marcados, há marcas de produção textual para a escola (GERALDI, 1997), em que se busca atender e agradar ao professor de Língua Portuguesa, o interlocutor real presente no processo dialógico, distanciando-se do interlocutor real externo, para quem a carta foi escrita, como correu com o texto 2: "Me despeço nesta carta de uma professora que me ensinou a gostar de geografia, que estudar também pode ser legal, en te acho uma ótima profissional'. Isso confirma a imprecisão e a presença de dois interlocutores na mesma carta, visto que o aluno se dirige à professora de Geografia: "não sei se irei gostar de geografia sem você estar ensinando, mas fico feliz e espero que consiga terminar o seu doutorado com sucesso e volte a dar aula para a gente." A proposta foi feita pela professora de Língua Portuguesa que estava presente no momento de construção do texto, logo, tudo isso influenciou diretamente na elaboração do discurso do aluno. Para esse aluno, não está claro o evento discursivo proposto - escrever uma carta para a professora de Geografia - aparecendo escolhas linguísticas para dois interlocutores - o real e o real externo. Além disso, marcas extras linguísticas precisariam ser consideradas, pois o segundo aluno é mais tímido que o primeiro e, provavelmente, mantenha um contato meramente de sala, nos momentos de aula de Geografia, dificultando a aproximação com o interlocutor professora, o que não ocorreu com a primeira carta, em que se explicitou o contato via Orkut e MSN, logo o 'horizonte social' dos dois é diferenciado.

No texto 2, o discurso evidencia uma interlocução artificial com a professora. Em relação às marcas que sugerem essa interlocução, tem-se:

- a professora ensinou que estudar é legal;

- a professora é brava com os alunos;

- o aluno deseja que a professora termine seu doutorado com sucesso. 
Dentre essas poucas marcas, apenas a segunda, que informa que a professora era brava com os alunos, relaciona-se às marcas do texto 1 . Assim, pode-se afirmar que o texto 2 não foi efetivamente produzido ao interlocutor eleito, mas sim à interlocutora real professora, apenas como processo avaliativo de sala de aula, o que é um risco possível nessa situação.

Outra marca de escrita para a escola está nas cartas, em que os alunos não as assinam, mantendo seus nomes apenas em um cabeçalho, no entanto, esse fato não é representativo, pois há somente duas ocorrências. Em uma delas, inclusive, o aluno não coloca o nome da professora de Geografia, apenas "Querida professora" (G.P.M.). Neste caso, há um distanciamento real marcado na carta, pois este aluno está apenas há seis meses estudando no colégio, diferentemente dos demais, que estão com a mesma professora desde o segundo semestre da $5^{a}$ série. Em várias cartas aparece esse tempo determinado: "Durante esses três anos você foi uma ótima professora e aprendi muita coisa em suas aulas" (A.F.), comprovando, portanto, a influência do interlocutor na enunciação.

Nessas produções, pudemos confirmar uma das assertivas de Antunes (2003, p. 45):

A atividade da escrita é, então, uma atividade interativa de expressão, (ex- 'para fora'), de manifestação verbal das ideias, informações, intenções, crenças ou dos sentimentos que queremos partilhar com alguém, para, de algum modo, interagir com ele.

pertencente ao mundo exterior e, além disso, provavelmente, em função desse gênero textual, não apareceram ocorrências de manifestações do interlocutor interno: "outro constituído quando o locutor dialoga com consigo próprio, ou seja, o interlocutor/interno é o outro de si próprio" (FRANZOI, 2009, p. 37).

\section{Considerações Finais}

As análises realizadas comprovam as teorias do Círculo de Bakhtin, ao apresentarem que a palavra "é uma espécie de ponte lançada entre mim e os outros. Se ela se apóia sobre mim numa extremidade, na outra apóia-se sobre o meu interlocutor" (BAKHTIN/VOLOCHINOV, 1992, p. 113), em uma situação social de compreensão responsiva ativa. As cartas pessoais 
dos alunos, mesmo possuindo um interlocutor delimitado, demonstraram marcas diferenciadas na enunciação, utilizando-se de 'várias pontes', primordialmente direcionando ao interlocutor real externo - professora Cleide, para quem a carta pessoal deveria ser encaminhada; mas, também, enunciações foram dirigidas a um interlocutor real - professora de Língua Portuguesa, presente no processo dialógico, quem aplicou a atividade. Ademais, foram encontradas marcas insignificantes de interlocutor virtual e nenhuma marca de interlocutor interior, fato que pode ser justificado por ser uma produção de Carta Pessoal.

Dessa forma, as características levantadas nessa experiência, em que se consideram dois interlocutores reais, são:

- os produtores das cartas empregam duas pessoas do discurso, como se dialogassem com dois interlocutores distintos;

- a delimitação do interlocutor permite ao produtor manifestar suas críticas ao interlocutor real externo de maneira objetiva;

- também é possível notar que o produtor consegue se expor significativamente, como nos pedidos de desculpas apresentados à professora de Geografia;

- as características pessoais do interlocutor real externo são objetivamente apresentadas pelo produtor;

- há interferência do interlocutor real professor no texto, evidenciadas por marcas linguístico-discursivas;

- o emprego do vocativo pelo cargo do interlocutor real externo, "professora", mobiliza a interlocução, em função de sua posição social definida;

- o produtor dialoga com dois interlocutores ao mesmo tempo, sem perder sua unidade temática no texto produzido.

Este trabalho comprovou que os procedimentos de escrita em sala de aula e o desenvolvimento da produção de textos dos alunos é um desafio contínuo e que os elementos essenciais para a construção textual, como a delimitação do interlocutor, precisam ser sempre apresentados aos alunos, para minimizar os problemas de escrita em uma interação comunicativa, pois, assim como confirmou Garcez (1998), os estudantes ainda apresentam um amadurecimento restrito da consciência da complexidade dos elementos que constituem um texto. Em uma reescrita, esses elementos poderiam ser pontuados aos alunos para melhorar o resultado final da produção escrita. 


\section{Referências}

ANTUNES, I. Aula de Português - encontro \& interação. São Paulo: Parábola Editorial, 2003.

BAKHTIN, M./VOLOCHINOV, V. N. Marxismo e Filosofia da Linguagem. 6. ed. São Paulo: Hucitec, 1992.

BAKHTIN, M. Estética da criação verbal. Tradução Paulo Bezerra. 4. ed. São Paulo: Martins Fontes, 2003.

FREITAS, M. T.A. Vygotsky \& Bakhtin. 4. ed. São Paulo: Ática, 2006.

FRANZOI, R. C. Manifestações do interlocutor nas producões textuais: escritas no ensino fundamental. 2009. Dissertação (Mestrado em Letras) Universidade Estadual de Maringá, Maringá.

GARCEZ, L. A escrita e o outro. Brasília: Editora Universidade de Brasília, 1998.

GERALDI, J. W. Da redação à produção de textos. In: GERALDI, J. W.; CITELLI, B. (Orgs.). Aprender e ensinar com textos de alunos. v. 1. São Paulo: Cortez, 1997. 1. p. 17- 24.

MARCHEZAN, M. R.; MOTTA-ROTH, D. O gênero contracapa na perspectiva teórica bakhtiniana. Revista Transdisciplinar de Letras, Educação e Cultura da UNIGRAN, Dourados, v. 10, n. 10. Disponível em: <http:// www.unigran.br/revistas/interletras/ed_anteriores/n10/edicao/vol10/ artigos/16.pdf>. Acesso em: 13 maio 2011.

MENEGASSI, R. J. A influência do interlocutor na produção de textos. Revista UNIMAR, v. 19, n.1, p. 111-125, 1997.

MENEGASSI, R. J. Professor e escrita: a construção de comandos de produção de textos. Trabalhos Linguística Aplicada, v. 42, p. 55-79, 2003.

MENEGASSI, R. J.; FUZA, A. F. A finalidade da escrita no livro didático: influências da imagem do Interlocutor. Acta Scientiarum. Human and Social Sciences, v. 28, n. 2, p. 155-165, 2006. 
PARANÁ. Secretaria de Estado de Educação do Paraná. Departamento de Educação Básica. Diretrizes Curriculares de Educação Básica: Língua Portuguesa. Curitiba: SEED, 2008.

ROJO, R. Gêneros do discurso e gêneros textuais: questões teóricas e aplicadas. In: MEURER, J. L.; BONINI, A.; MOTTHA-ROTH, D.

(Orgs.). Gêneros, teorias, métodos, debates. São Paulo: Parábola Editorial, 2005. p. 184-207.

SOUZA, I. R. Conceitos bakbtinianos no contexto da reformulação curricular da Educação Básica do Paraná. 2010. Dissertação (Mestrado em Letras) Universidade Estadual de Maringá, Maringá.

VOLOSHINOV/BAKHTIN. Discurso na vida e discurso na arte (sobre poética sociológica). Tradução Carlos Alberto Faraco e Cristóvão Tezza. 1976 [1926]. (Circulação restrita).

ZANINI, M. O texto como unidade de objeto de ensino. In: ANTONIO, J. D.; NAVARRO, P. (Orgs.). O texto como objeto de ensino, de descrição linguística e de análise textual e discursiva. Maringá: Eduem, 2009. p. 13-25. 